\title{
RESEARCH
}

Open Access

\section{ROCK2 deprivation leads to the inhibition of tumor growth and metastatic potential in osteosarcoma cells through the modulation of YAP activity}

Cinzia Zucchini ${ }^{1 *+}$, Maria Cristina Manara ${ }^{2+}$, Camilla Cristalli ${ }^{2}$, Marianna Carrabotta ${ }^{2}$, Sara Greco $^{2}$, Rosa Simona Pinca ${ }^{2}$, Cristina Ferrari ${ }^{2}$, Lorena Landuzzi ${ }^{2}$, Michela Pasello², Pier-Luigi Lollini ${ }^{1}$, Marco Gambarotti ${ }^{3}$, Davide Maria Donati ${ }^{4,5}$ and Katia Scotlandi ${ }^{2 *}$

\begin{abstract}
Background: The treatment of metastatic osteosarcoma (OS) remains a challenge for oncologists, and novel therapeutic strategies are urgently needed. An understanding of the pathways that regulate OS dissemination is required for the design of novel treatment approaches. We recently identified Rho-associated coiled-coil containing protein kinase 2 (ROCK2) as a crucial driver of OS cell migration. In this study, we explored the impact of ROCK2 disruption on the metastatic capabilities of OS cells and analyzed its functional relationship with Yes-associated protein-1 (YAP), the main transcriptional mediator of mechanotransduction signaling.

Methods: The effects of ROCK2 depletion on metastasis were studied in NOD Scid gamma (NSG) mice injected with U-2OS cells in which ROCK2 expression had been stably silenced. Functional studies were performed in vitro in human U-2OS cells and in three novel cell lines derived from patient-derived xenografts (PDXs) by using standard methods to evaluate malignancy parameters and signaling transduction. The nuclear immunostaining of YAP and the evaluation of its downstream targets Cysteine Rich Angiogenic Inducer 6, Connective Tissue Growth Factor and Cyclin D1 by quantitative PCR were performed to analyze YAP activity. The effect of the expression and activity of ROCK2 and YAP on tumor progression was analyzed in 175 OS primary tumors.

Results: The silencing of ROCK2 markedly reduced tumor growth and completely abolished the metastatic ability of U-2OS cells. The depletion of ROCK2, either by pharmacological inhibition or silencing, induced a dose- and time-dependent reduction in the nuclear expression and transcriptional activity of YAP. The nuclear expression of YAP was observed in 80/175 (46\%) tumor samples and was significantly correlated with worse patient prognosis and a higher likelihood of metastasis and death. The use of verteporfin, a molecule that specifically inhibits the TEAD-YAP association, remarkably impaired the growth and migration of OS cells in vitro. Moreover to inhibiting YAP activity, our findings indicate that verteporfin also affects the ROCK2 protein and its functions.

(Continued on next page)
\end{abstract}

\footnotetext{
* Correspondence: cinzia.zucchini@unibo.it; katia.scotlandi@ior.it

${ }^{+}$Cinzia Zucchini and Maria Cristina Manara contributed equally to this work

${ }^{1}$ Department of Experimental, Diagnostic and Specialty Medicine, (DIMES),

University of Bologna, Via Massarenti 9, 40126 Bologna, BO, Italy

${ }^{2}$ Experimental Oncology Laboratory, IRCCS Istituto Ortopedico Rizzoli, via di

Barbiano 1/10, 40136 Bologna, Italy

Full list of author information is available at the end of the article
}

C The Author(s). 2019 Open Access This article is distributed under the terms of the Creative Commons Attribution 4.0 International License (http://creativecommons.org/licenses/by/4.0/), which permits unrestricted use, distribution, and reproduction in any medium, provided you give appropriate credit to the original author(s) and the source, provide a link to the Creative Commons license, and indicate if changes were made. The Creative Commons Public Domain Dedication waiver (http://creativecommons.org/publicdomain/zero/1.0/) applies to the data made available in this article, unless otherwise stated. 
(Continued from previous page)

Conclusions: We describe the functional connection between ROCK2 and YAP in the regulation of OS cell migration and metastasis formation. These data provide support for the use of verteporfin as a possible therapeutic option to prevent OS cell dissemination.

Keywords: Osteosarcoma, ROCK2, YAP, Verteporfin, Metastasis,

\section{Background}

Osteosarcoma (OS), a highly aggressive malignant tumor that develops in the bone, preferentially occurs in children and young adults. The prognosis for patients has improved greatly during the past three decades due to the advancement of neoadjuvant and adjuvant chemotherapy in conjunction with surgery, and at present, the 5-year event-free survival rate has reached approximately $70 \%$ for patients with localized disease [1-3]. However, the prognosis for metastatic patients remains grim, and the survival rates for patients who present metastases at the time of diagnosis are below 30\% [4]. Thus, treating metastatic OS remains a challenge for oncologists, and a deeper understanding of the biology underlying metastasis in OS is an urgent need for the development of novel and more targeted therapeutic options.

The ability of cancer cells to spread to secondary organs outside of the primary tumor site requires mechanical forces exerted via actin cytoskeleton dynamics. The actin status is used as a signaling intermediary by a variety of pathways associated with cancer cell dissemination and metastasis, including the Hippo signaling pathway, an oncosuppressive pathway that plays multiple critical roles in the control of cellular malignancy. Canonical Hippo transduction involves a cascade of serine/threonine kinases that phosphorylate and inhibit Yes-associated protein-1 (YAP) and its coactivator TAZ, promoting their cytoplasmic retention and/or subsequent degradation. When Hippo signaling is 'off, YAP and TAZ translocate to the nucleus, where they interact with the transcription factors TEAD1-4 to induce the expression of target genes responsible for cellular proliferation, differentiation and survival [5]. The dysregulation of Hippo signaling and/or YAP activity occurs frequent in a variety of human cancers [6], including OS, as YAP is highly expressed in both human and mouse OS. YAP suppression sharply decreases cell proliferation, cancer stemness and tumorigenicity [79], thereby acting as a potential therapeutic target for tumors. In addition to operating in Hippo signaling, YAP also senses and mediates the integrity of the actomyosin cytoskeleton and the intracellular mechanotransduction pathway [10-13]. The actin status is also controlled by the Rho/Rho-associated coiled-coil containing protein kinase (ROCK) pathway, which can sustain and promote YAP activity through the phosphorylation of several molecular targets that are induced by Rho-associated coiled-coil containing protein kinase 1 and 2 (ROCK1 and ROCK2) $[11,14]$. Thus, the Hippo pathway, the cytoskeleton, Rho/ ROCK and YAP/TAZ may form a complex molecular network of multilayered interactions with feedback mechanisms, whose connections are still poorly understood and may differ in diverse cellular contexts. In OS, we have previously highlighted the importance of ROCK2, rather than ROCK1, as a crucial mediator of cell migration and invasion [15]. In this study, we analyzed the impact of ROCK2 depletion on OS metastasis and its functional connections with YAP activity. We also tested verteporfin, a small molecule that specifically inhibits the TEAD-YAP association [16], as a potential therapeutic agent for OS.

\section{Methods \\ Cell lines}

The U-2OS OS cell line was obtained from the American Type Culture Collection (ATCC). The primary cultures PDX-OS\#2-C1, PDX-OS\#16-C2 and PDX-OS\#25-C1 were recently obtained from OS patient-derived xenografts (PDXs) after one or two passages in animals [17]. Patient informed consent was obtained for the establishment of the PDX models. All cell lines were tested for mycoplasma contamination (Mycoalert Mycoplasma Detection Kit, Lonza) before use. Cell lines were immediately expanded to generate liquid nitrogen stocks and were never passaged for more than 1 month after thawing. Cells were grown in Iscove's modified Dulbecco's medium (IMDM) supplemented with 10\% inactivated fetal bovine serum (FBS) (Euroclone), 100 units $/ \mathrm{ml}$ penicillin and $100 \mu \mathrm{g} / \mathrm{ml}$ streptomycin (Sigma). Cells were maintained at $37^{\circ} \mathrm{C}$ in a humidified $5 \% \mathrm{CO}_{2}$ atmosphere.

\section{Stable silencing}

For stable silencing, a short hairpin RNA (shRNA) plasmid (pSilencer 2.1-U6 Neo vector; Ambion) expressing ROCK2 siRNA (Fw: 5'-GATCCCGGCAACTGGCTCGTTCAATT TTCAAGAGA TTAACTTGCTCGGTCAACGTTTTTTG GAA-3'; Rw: 5'-AGCTTTTCCAAAAAACGTTGACCG AGCAAGTTAATCTCTTGAAAATTGAACGAGCCAGT TGCCGG-3') was created, and U-2OS cells were transfected using the calcium phosphate transfection method (Life Technologies). Stable transfectants expressing shRNA-ROCK2 (U-2/shROCK2\#78 and \#46) or nontargeting shRNA 
sequences (U-2/SCR pool) were obtained after selection in neomycin $(500 \mu \mathrm{g} / \mathrm{ml})$ (Sigma).

\section{Treatments}

For transient ROCK2 silencing, cells were transfected with small interfering RNA (siRNA) sequences targeting ROCK2 (ON-TARGETplus SMARTpool, Human ROCK2, Dharmacon) or irrelevant targets (ON-TARGETplus Non-targeting siRNA). For ROCK2 inhibition, the ROCK2 inhibitor N-(2(2-(dimethylamino)ethoxy)-4-(1H-pyrazol-4-yl)phenyl)-2, 3dihydrobenzo[b]1, 4 dioxine-2-carboxamide (Stemolecule ROCK2 Inhibitor, Stemgent) was used. To inhibit YAP activity, tests were performed with the YAP inhibitor verteporfin (Sigma). Both compounds were dissolved in dimethyl sulfoxide (DMSO; Sigma-Aldrich). Working solutions were prepared in IMDM immediately before use.

\section{Motility assay}

Cells $\left(1 \times 10^{5}\right)$ were pretreated with or without the YAP inhibitor verteporfin $(2 \mu \mathrm{M})$ for $24 \mathrm{~h}$, after which they were analyzed for their migration ability. A motility assay was performed using Transwell chambers (Costar) with $8-\mu \mathrm{m}$ pore size polyvinylpyrrolidone-free polycarbonate filters (Nucleopore). Cells were seeded in IMDM with 10\% FBS in the upper compartment and were incubated for $18 \mathrm{~h}$ at $37^{\circ} \mathrm{C}$. The number of cells that migrated toward the filter to reach the lower chamber was counted after fixation with methanol and staining with Giemsa (Sigma).

\section{Wound-healing assay}

A total of $2 \times 10^{5} \mathrm{U}-2 \mathrm{OS}$ cells were seeded in $60-\mathrm{mm}$ Petri-dish well plates. Cells were allowed to grow to $100 \%$ confluence. The cell monolayer was scraped in a straight line to create a scratch with a p200 pipet tip. The debris was removed, and the medium was replaced with IMDM with $10 \%$ FBS with or without $2 \mu \mathrm{M}$ verteporfin. Cells were kept in a tissue culture incubator at $37^{\circ} \mathrm{C}$, and pictures were taken at 0,3 and $6 \mathrm{~h}$.

\section{Cell growth inhibition}

To perform cell culture experiments, OS cells $\left(2 \times 10^{5} /\right.$ well for U-2OS or $4 \times 10^{5}$ /well for PDX-OS primary cultures) were plated, and verteporfin $(0.1-10 \mu \mathrm{M})$ was added after $24 \mathrm{~h}$. Cells were exposed to the drug for up to $96 \mathrm{~h}$ before being counted by Trypan blue vital dye exclusion (Sigma). In parallel, cells were treated with DMSO-containing medium as a control. The highest final concentration of DMSO in the medium was $<0.3 \%$, and DMSO had no effect on cell growth.

Anchorage-independent growth was measured in $0.33 \%$ agarose (Sea-Plaque; Lonza) with a $0.5 \%$ agarose underlay. OS cells $(10,000$ for U-2OS or 100,000 for PDX-OS\#16-C2) were plated in semisolid medium with or without verteporfin $(2 \mu \mathrm{M})$ and were incubated at $37^{\circ} \mathrm{C}$ in a humidified $5 \% \mathrm{CO}_{2}$ atmosphere. Colonies were counted after 10 and 14 days for U-2OS or PDXOS\#16-C2, respectively.

\section{Immunofluorescence}

Cells grown on coverslips were treated with verteporfin as described above. Cells were fixed in $4 \%$ paraformaldehyde were permeabilized with $0.15 \%$ Triton X-100 (Sigma) in phosphate-buffered saline or in methanol and were incubated with the following antibodies: anti-YAP (sc-271134, dilution 1:25), anti- $\beta$-catenin (sc-7963, dilution 1:50), and anti-ROCK2 (sc-398,519, dilution 1:50) that were all purchased from Santa Cruz Biotechnologies; and anti-N-cadherin (BD Transduction Labs, 610921, dilution 1:100). Anti-mouse FITC (Thermo Scientific, \#31569, dilution 1:100) or anti-goat IgG NL493 (FITC equivalent R\&D, \#NL003, dilution 1:50) were used as secondary antibodies. Nuclei were counterstained with Hoechst 33256 (Sigma). Images were acquired using a Nikon ECLIPSE 90i microscope and were then analyzed with NIS-Elements software (Nikon).

\section{In vivo experiments}

Female, 5 weeks old, immunodeficient NOD Scid gamma (NSG) mice were obtained from Charles River, Italy. Groups of 6 mice received injections of $10^{7} \mathrm{U}$ $2 \mathrm{OS}$ cells subcutaneously. Tumor growth was measured weekly and tumor volumes were calculated as $\pi /$ $2 \cdot[\sqrt{ }(\mathrm{a} \cdot \mathrm{b})]^{3} / 6$, where $\mathrm{a}$ and $\mathrm{b}$ are the two maximal diameters. After $9-10$ weeks, animals were sacrificed by $\mathrm{CO}_{2}$ inhalation and cervical dislocation, and an accurate necropsy was performed. Tumors were removed for further studies; lungs were perfused with black India ink and fixed. Lung metastases were then counted under a dissecting microscope.

\section{RNA extraction and qPCR}

Total RNA from snap-frozen tissue samples and cell lines was isolated using TRIzol Reagent (Thermo Fisher Scientific - Life Technologies). RNA quality and quantity were assessed by NanoDrop analysis (NanoDrop ND1000, Thermo Scientific) and by electrophoresis. Total RNA from each sample was reverse transcribed into complementary DNA (cDNA) using a High-Capacity cDNA Reverse Transcription Kit (Thermo Scientific - Applied Biosystems, \#4368814) according to the manufacturer's protocols. Quantitative PCR (qPCR) was performed on a ViiA7 system (Life Technologies) using TaqMan Universal PCR Master Mix (Thermo Fisher Scientific - Applied Biosystems, \#4304437) and SYBR Green PCR Master Mix (Thermo Fisher Scientific - Applied Biosystems, \#4312704). Predesigned TaqMan probes (Thermo Fisher Scientific - Applied Biosystems) were used for Connective Tissue Growth Factor (CTGF) (Hs00170014) 
Cysteine Rich Angiogenic Inducer 61 (CYR61) (Hs00155479) and Cyclin D1 (CCND1) (Hs00765553). The primers used are ROCK2 forward 5' - CAACTGTGAGGCTTGTATGA AG-3' and reverse 5'-TGCAAGGTGCTATAATCTCCTC3'; GAPDH forward: 5'-GAAGGTGAAGGTCGGAGTC3', reverse: 5'-GAAGATGGTGATGGGATTTC-3'.Relative quantification was performed in tumor samples with the $\triangle \mathrm{CT}$ method (relative abundance, $\mathrm{RA}=2^{-}{ }^{-\mathrm{CT}}$ ) while the $\Delta \Delta C T$ method (relative quantification, $R Q=2^{-} \Delta \Delta C T$ ) was used for cell line analysis. The expression levels of the target genes were normalized to those of the housekeeping gene GAPDH (Hs99999905_m1). Untreated cells (CTRL) or cells exposed to an shRNA against irrelevant targets (SCR) were used as controls.

\section{Western blotting}

Subconfluent cells were treated as described above and were processed for Western blotting following standard procedures, using total protein lysates or fractionated proteins, where appropriate. Cytoplasmic proteins were obtained using the lysis buffer containing $50 \mathrm{mmol} / \mathrm{L}$ HEPES (pH 7.5), $150 \mathrm{mmol} / \mathrm{L} \mathrm{NaCl}, 1 \%$ Triton X-100, $1.5 \mathrm{mmol} / \mathrm{L} \mathrm{MgCl}$, EGTA, $10 \mathrm{mmol} / \mathrm{L}$ (pH 7.5), glycerol $10 \%$, and inhibitors $(0.1 \mathrm{mmol} / \mathrm{L} \mathrm{Na} 3 \mathrm{VO} 4,1 \%$ phenylmethylsulfonyl fluoride, and $20 \mathrm{mg} / \mathrm{mL}$ aprotinin). After the collection of cytoplasmic proteins, the nuclei were lysed with the nuclear buffer containing $20 \mathrm{mmol} / \mathrm{L}$ HEPES (pH 8), $0.1 \mathrm{mmol} / \mathrm{L}$ EDTA, $5 \mathrm{mmol} / \mathrm{L} \mathrm{MgCl} 2$, $0.5 \mathrm{~mol} / \mathrm{L} \mathrm{NaCl}, 20 \%$ glycerol, $1 \%$ Nonidet $\mathrm{P} 40$, and inhibitors (as above). The following primary antibodies were used: anti-ROCK2 (Abcam, \#ab125025, dilution 1: 12000); anti-YAP (Cell Signaling, \#14074, dilution 1: 1000) anti-GAPDH (Santa Cruz, sc-25,778, dilution 1: 5000) and anti-Lamin B (Santa Cruz, sc-6216, dilution 1: 5000). Anti-rabbit (GE Healthcare, \#NA934), anti-mouse (GE Healthcare, \#NA931) or anti-goat (Santa Cruz, sc2020) secondary antibodies conjugated to horseradish peroxidase were used, and bands were visualized with enhanced chemiluminescence Western blotting detection reagents (EuroClone).

\section{Patients}

Patients with localized primary OS who were enrolled in prospective studies and were treated at the Rizzoli Institute were included in the current analysis. The present study included 175 tumor samples from biopsy specimens (obtained before chemotherapy and preserved in archival paraffin-embedded tissue blocks) that were available for immunohistochemical analysis and had adequate tissue. All tumors were classified as stage II conventional high-grade OS [18]. Chemotherapy was given before and after surgery. Chemotherapy protocols based on doxorubicin, high-dose methotrexate, cisplatin and/ or ifosfamide have been previously described [19-22].
The surgical procedures took into account the location and extent of the tumor and the life expectancy of the patient. A limb-salvage procedure was performed in 158 patients (90\%). The surgical margins of the tumor specimens were histologically defined according to the system of Enneking [18]. The extent of tumor necrosis was evaluated with a previously described semiquantitative method [23]. Adverse events were defined as a recurrence of the tumor at any site (local or systemic) or death during remission. Relapse-free survival (RFS) was calculated from the date of the initial diagnosis. The median follow-up of the population was 95 months (range 2-415 months). Clinical and follow-up data were updated until December 2018. The rates of RFS and overall survival (OVS) were 51.4 and $69.7 \%$, respectively. Table 1 summarizes the clinical and pathological characteristics of the 175 patients.

\section{Immunohistochemistry}

An avidin-biotin-peroxidase procedure was used for immunostaining (Vector Laboratories). Antigen retrieval was performed using citrate buffer ( $\mathrm{pH}$ 6.0), followed by incubation with anti-YAP (sc-271134, dilution 1:50) or anti-ROCK2 (sc-398,519, dilution 1:50). In human tumor samples, we used a semiquantitative score for YAP immunostaining to evaluate its level of expression together with an analysis of its intracellular location to evaluate its activity. Patients were classified as positive when the nuclear positivity of YAP was detected. The expression levels were scored as follows: negative, when no staining was observed; positive, including weak (+- ), moderate $(++-)$, and strong $(+++)$ positivity levels.

\section{Statistical analysis}

Differences among the means were analyzed using Student's $t$ tests. For analysis of incidence and median number of lung metastasis Fisher's exact test and Wilcoxon's rank sum test were used. CalcuSyn2 software (Biosoft) was used to calculate the $\mathrm{IC}_{50}$ values. The association between YAP expression and RFS or OVS was estimated by Cox proportional hazards regression analysis. RFS and OVS were plotted using the Kaplan-Meier method, while the log-rank test was used to calculate the univariate statistical significance of the observed differences. RFS was calculated as the time from diagnosis to the occurrence of adverse events, which were defined as recurrence or metastases at any site. OVS was defined as the time from diagnosis to cancer-related death. Survivors or patients who were lost to follow-up were censored at the last contact date. All factors that were significantly associated with RFS in the univariate analysis were entered into a Cox proportional hazards model for multivariate analysis. Values for the $95 \%$ confidence interval (CI) of the hazard ratios (HRs) are provided [24]. The Chi square test was 
Table 1 Clinicopathological features of OS patients evaluated for YAP expression by immunohistochemistry (IHC) in 175 tissue samples

\begin{tabular}{|c|c|c|c|c|}
\hline Characteristics & $\mathrm{N}$ & $\%$ & Association with prognosis (RFS) & Association with survival $(\mathrm{OVS})^{\mathrm{b}}$ \\
\hline Gender & & & $P=0.67$ & $P=0.92$ \\
\hline Female & 72 & 41.1 & & \\
\hline Male & 103 & 58.9 & & \\
\hline Age & & & $P=0.37$ & $P=0.10$ \\
\hline$\leq 14$ years & 82 & 46.9 & & \\
\hline$>14$ years & 93 & 53.1 & & \\
\hline Surgery & & & $P=0.47$ & $P=0.91$ \\
\hline Resection & 158 & 90.3 & & \\
\hline Amputation & 12 & 6.9 & & \\
\hline Rotation plastic & 5 & 2.8 & & \\
\hline Margins & & & $P=0.10$ & $P=0.36$ \\
\hline Adequate & 147 & 84.0 & & \\
\hline Inadequate & 28 & 16.0 & & \\
\hline Chemotherapy response (Necrosis) & & & $P=0.05$ & $P=0.21$ \\
\hline Good & 105 & 60.0 & & \\
\hline Poor & 69 & 39.4 & & \\
\hline NA & 1 & 0.6 & & \\
\hline \multicolumn{5}{|l|}{ RFS (status) } \\
\hline NED & 90 & 51.4 & & \\
\hline REL & 85 & 48.6 & & \\
\hline \multicolumn{5}{|l|}{ OVS (status) } \\
\hline Living & 122 & 69.7 & & \\
\hline Dead & 53 & 30.3 & & \\
\hline
\end{tabular}

Associations with prognosis were calculated by univariate analysis using the log-rank test

OS osteosarcoma, NED no evidence of disease, REL relapsed, RFS relapse-free survival, OVS overall survival

${ }^{a}$ RFS (median follow-up: 95 months; range 2-415 months)

${ }^{b}$ OVS (median follow-up: 156 months; range 7-415 months)

used for association data. Statistical analyses were performed with SPSS software, version 22.0.

\section{Results}

ROCK2 deprivation inhibits the in vivo growth and metastatic ability of OS cells through the modulation of YAP activity

The stable silencing of ROCK2 was induced in U-2OS cells to evaluate the impact of this kinase on the metastatic capability of OS cells. Cells transfected with nontargeting shsequences were used as controls. The depletion of ROCK2 markedly reduced tumor growth when tumor cells were injected into immunodeficient NSG mice (Fig. 1a; Table 2) and completely abolished the pulmonary metastatic potential of these cells (Fig. 1b; Table 2). According to our previous observations, ROCK2-silenced OS cells (namely, U-2/ shROCK2\#46 and U-2/shROCK2\#78) showed increases in the expression and cell-membrane recruitment of $\mathrm{N}$ cadherin and $\beta$-catenin, a weak migration capability in Transwell chambers, and a weak ability to form colonies in anchorage-independent conditions (Additional file 1: Figure S1). In U-2/shROCK2 tumors, YAP expression was remarkably decreased (Fig. 1c, d and Additional file 2: Figure S2), and its activity was inhibited, as indicated by a decrease in the expression of the YAP/TEAD-regulated genes CTGF and $C C N D 1$ (Fig. 1e). Consistently, we observed a remarkable reduction in the expression and activity of YAP either when ROCK2 was inhibited by the specific Stemolecule ROCK2 inhibitor [15] or by the transient exposure of cells to siRNA sequences. In addition to the immunofluorescence analysis (Fig. 2a), biochemical fractionation of nuclear and cytoplasmic fractions after ROCK2 inhibition clearly showed the time-dependent nuclear abrogation of YAP expression (Fig. 2b). Accordingly, the expression of the YAPTEAD-regulated genes CTGF, CYR61 and CCND1 was found to be significantly inhibited when ROCK2 activity is hampered (Fig. 2c), confirming the functional association between ROCK2 and YAP activity. The inhibition of the YAP targets was maintained for at least until $72 \mathrm{~h}$ after the cell treatments. 


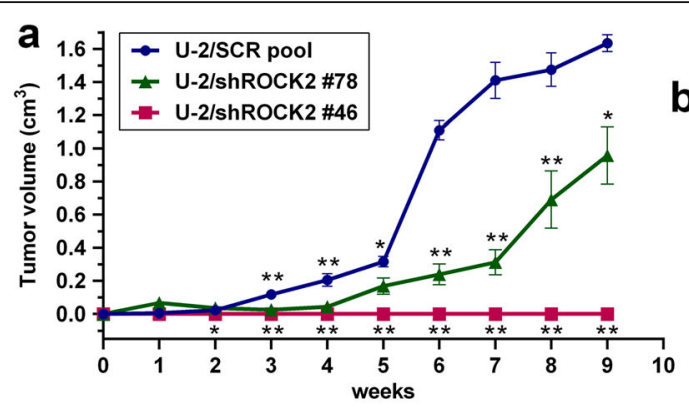

b

U-2/SCR pool U-2/shROCK2 \#46 U-2/shROCK2 \#78

C

ROCK2
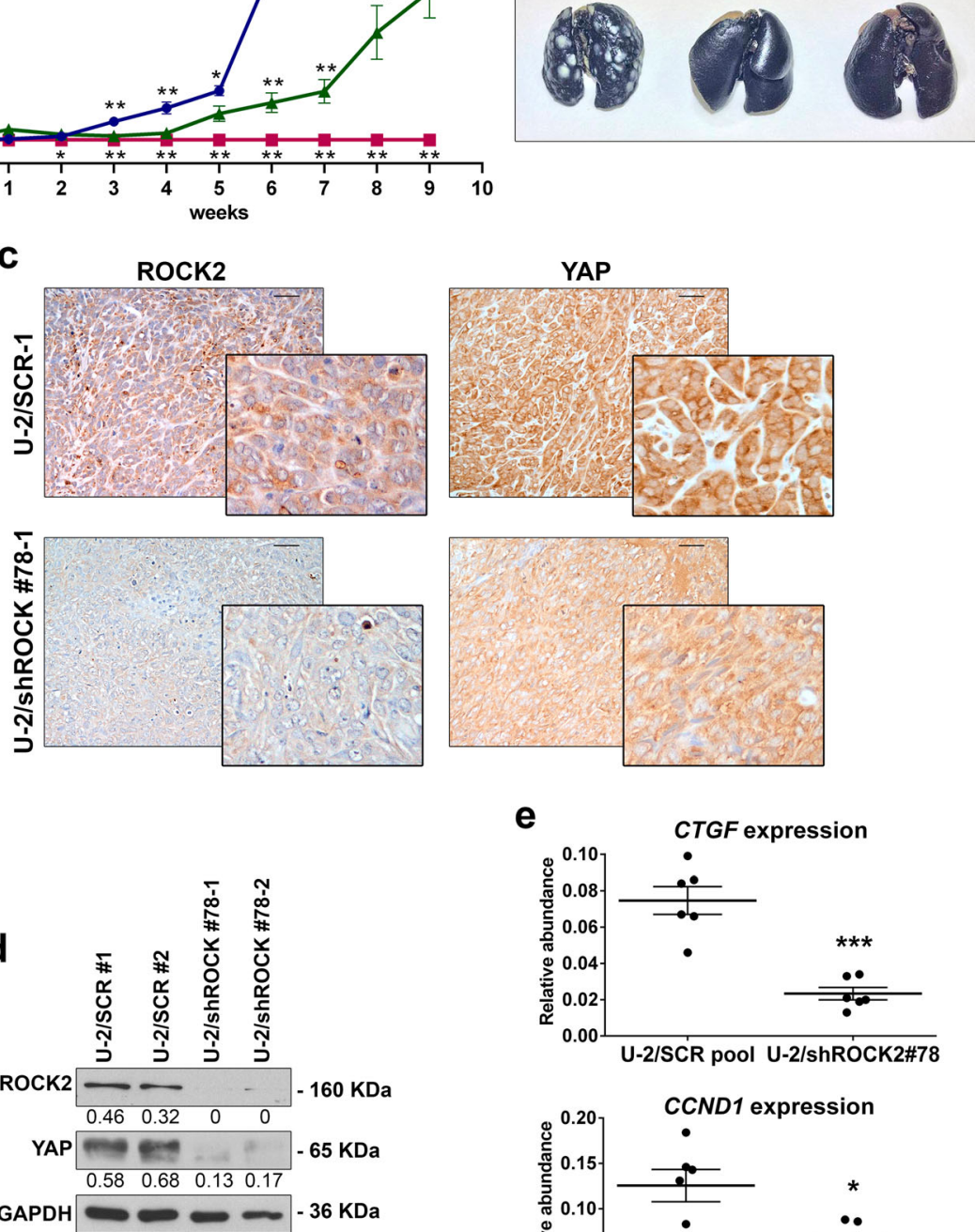

e
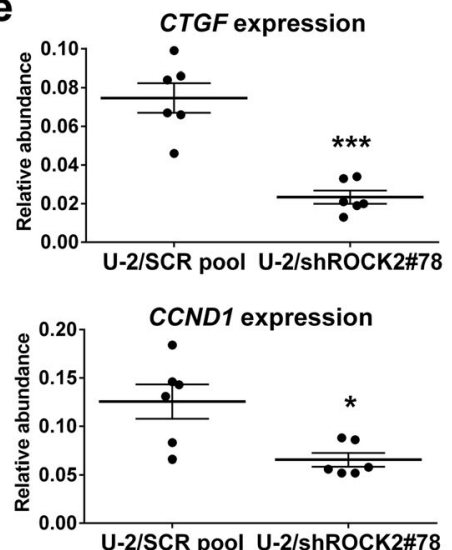

Fig. 1 Silencing ROCK2 in OS cells impairs tumor growth and metastasis in mice and downregulates YAP expression and activity. a Tumor volume and $\mathbf{b}$ representative images of lung metastases of mice injected subcutaneously with U-2OS cells modified for ROCK2 expression. $n=6$ animals per group. ${ }^{*} p<0.05,{ }^{* *} p<0.001$ vs. control (U-2/SCR pool) by the Student's $t$ test. c ROCK2 and YAP expression were evaluated by the immunostaining of paraffin-embedded tissue samples. Representative images from one tumor developed after injection of control (U-2/SCR) or silenced cells (U-2/shROCK2\#78). Scale bar, $50 \mu \mathrm{m} ; 200 x$ of magnification with zoomed insert to show details. d Western blotting of snap-frozen tissue samples from two representative tumors that formed in mice injected with control (U-2/SCR) or silenced cells (U-2/shROCK2\#78). GAPDH was used as a loading control. ROCK2 or YAP signals were quantified against GAPDH and reported as ratio of adjusted volume optical density $\left(\mathrm{OD} / \mathrm{mm}^{2}\right)$. e YAP activity was evaluated by measuring the relative mRNA expression of its downstream targets CTGF and CCND1 by qPCR. Scatter plot analysis of their expression in the control and U-2shROCK2\#78-derived xenografts $(n=6)$ is shown. The $2^{-\Delta C T}$ method, where $\Delta C T=C T$ target gene $-\mathrm{CT}$ GAPDH, was used. Bars represent mean $\pm \mathrm{SE},{ }^{*} p<0.05$, ${ }^{* * *} p<0.001$, Student's t test

\section{YAP activation is associated with a worse prognosis for OS patients}

Positivity for YAP immunostaining, either at the cytoplasmic or nuclear level, was detected in the majority of primary OS $(131 / 175 ; 75 \%)$, while the nuclear localization of the protein, which is directly related to its activity [5], was found in 80 out of 175 patients (46\%). Adverse metastatic events occurred in 42 of the $80(53 \%)$ patients with nuclear YAP expression and in 34 of the $95(36 \%)$ patients with inactive YAP ( $P=0.026$, Chi square test). Accordingly, KaplanMeier curves (Fig. 3a) confirmed that the presence of 
Table 2 Tumorigenicity and metastatic ability of U-2OS cells after the depletion of ROCK2

\begin{tabular}{|c|c|c|c|c|c|c|}
\hline \multirow[t]{2}{*}{ Cells } & \multicolumn{3}{|l|}{ Tumor } & \multicolumn{3}{|c|}{ Lung metastases } \\
\hline & Incidence & $\begin{array}{l}\text { Latency (mean days } \pm \\
\text { SEM) }\end{array}$ & $\begin{array}{l}\text { Volume at } 9 \text { weeks } \\
\text { (mean } \\
\mathrm{cm}^{3} \pm \text { SEM) }\end{array}$ & Incidence & $\begin{array}{l}\text { Median } \\
\text { number }\end{array}$ & Individual values \\
\hline U-2/SCR pool & $6 / 6$ & $23.2 \pm 1.2$ & $1.635 \pm 0.051$ & $6 / 6$ & $>200$ & $\begin{array}{l}>200,>200,>200,>200,>200,> \\
200\end{array}$ \\
\hline $\begin{array}{l}\text { U-2/sh ROCK2 } \\
\# 78\end{array}$ & $6 / 6$ & $37 \pm 2.9$ & $0.958 \pm 0.233^{*}$ & $0 / 6+$ & $0 \neq$ & $0,0,0,0,0,0$ \\
\hline $\begin{array}{l}\text { U-2/sh ROCK2 } \\
\# 46\end{array}$ & $0 / 6$ & NA & $0^{* *}$ & $0 / 6+$ & $0 \neq$ & $0,0,0,0,0,0$ \\
\hline
\end{tabular}

tp $=0.01$, Fisher's exact test, vs U-2/SCR pool

${ }^{*} p<0.05,{ }^{* *} p<0.0001$, Student's t test, vs. U-2/SCR pool

$\neq p<0.01$, Wilcoxon's rank sum test, vs. U-2/SCR pool

YAP in the nucleus of OS cells was significantly associated with a decreased probability of remaining event-free after diagnosis $(P=0.028$, log-rank test). Cox multivariate regression analysis was performed for the variables that were found to be associated with RFS by univariate analysis and showed that the nuclear status of YAP was the only independent risk factor for poor outcomes (Table 3). To further confirm this observation, we used the strong expression of YAP in the nucleus $(++/-$ and +++$)$ to stratify patients as high-expressors $(\mathrm{H})$ or low-expressors/nonexpressors (L/N) (47 vs 128 patients). Kaplan-Meier curves confirmed that very high YAP expression in the nucleus significantly affected both RFS and OVS in OS patients (Fig. 3b), indicating that the level of YAP activity is critical for patient outcomes. Consistently, the percentage of patients who died from this disease was significantly higher in those with high levels of active YAP (dead patients: $21 / 47,45 \%$ vs $32 /$ $128,25 \%$, respectively; $p=0.012$, Chi square test).

\section{Targeting YAP with verteporfin inhibits the malignancy of OS cells}

To test the therapeutic potential of YAP inhibition in OS, we used verteporfin, a porphyrin compound that was reported to block YAP-TEAD interactions [16]. Verteporfin effectively reduced U-2OS cell viability, with an IC50 value of $1.44 \pm 0.46 \mu \mathrm{M}$. As demonstrated in other tumors, including synovial sarcoma [25], verteporfin led to a dose- and time-dependent reduction in the expression (Fig. 4a) and activity (Fig. 4b) of YAP. Notably, verteporfin was also able to induce a dose- and time-dependent decrease in ROCK2 expression both at mRNA (Additional file 3: Figure S3) and protein levels (Fig. 4c, d), confirming the functional interconnection between YAP and ROCK2. Verteporfin treatment significantly inhibited the anchorageindependent growth of OS cells (Fig. 5a) and completely abrogated the migration of these cells (Fig. $5 \mathrm{~b}$ and $\mathrm{c})$. Cells treated with verteporfin showed increased expression and cell-membrane recruitment of $\mathrm{N}$-cadherin and $\beta$-catenin (Fig. $5 \mathrm{~d}$ ), thereby displaying the same phenotype that was previously observed after ROCK2 depletion (Additional file 1: Figure S1).

To build on our observations, we confirmed the growth-suppressive effects of verteporfin in three cell lines derived from PDXs, which have been reported to model the genetic features of human tumors, including bone sarcomas, with a high level of fidelity [17, 26-29]. Verteporfin effectively suppressed the cell growth of all three cell lines under standard conditions, with IC50 values ranging from 1 to $2 \mu \mathrm{M}$. In addition, in PDXOS\#16-C2, which expressed the highest levels of ROCK2 and YAP (Additional file 4: Figure S4), verteporfin completely suppressed the capability of these cells to form colonies and to migrate (Fig. 5e).

\section{Discussion}

ROCK2 kinase has been described as a critical mediator of biological functions that are implicated in the metastatic processes, including the disruption of adherens junctions, actin cytoskeleton remodeling, the dissociation of cell clusters and increased cell motility $[30,31]$. In OS, we have previously shown that ROCK2 is a crucial intracellular mediator of the CD99induced suppression of cell migration [15]. The inhibition of ROCK 2 was shown to impair the migratory and adhesive behavior of OS cells by decreasing the expression of ezrin, an actin-binding protein that leads to cytoskeletal regulation, and by recruiting $\mathrm{N}$ cadherin and $\beta$-catenin to the cell membrane. In this study, we expanded these observations and showed that when ROCK2 expression was stably downregulated in OS cells, tumor growth was significantly inhibited in NSG mice and, notably, tumors completely lost the capability to disseminate and to form spontaneous metastases in the lungs. These results strongly support the idea of specifically targeting ROCK2 kinase to prevent the formation of metastasis in OS. Although neoadjuvant chemotherapy has 


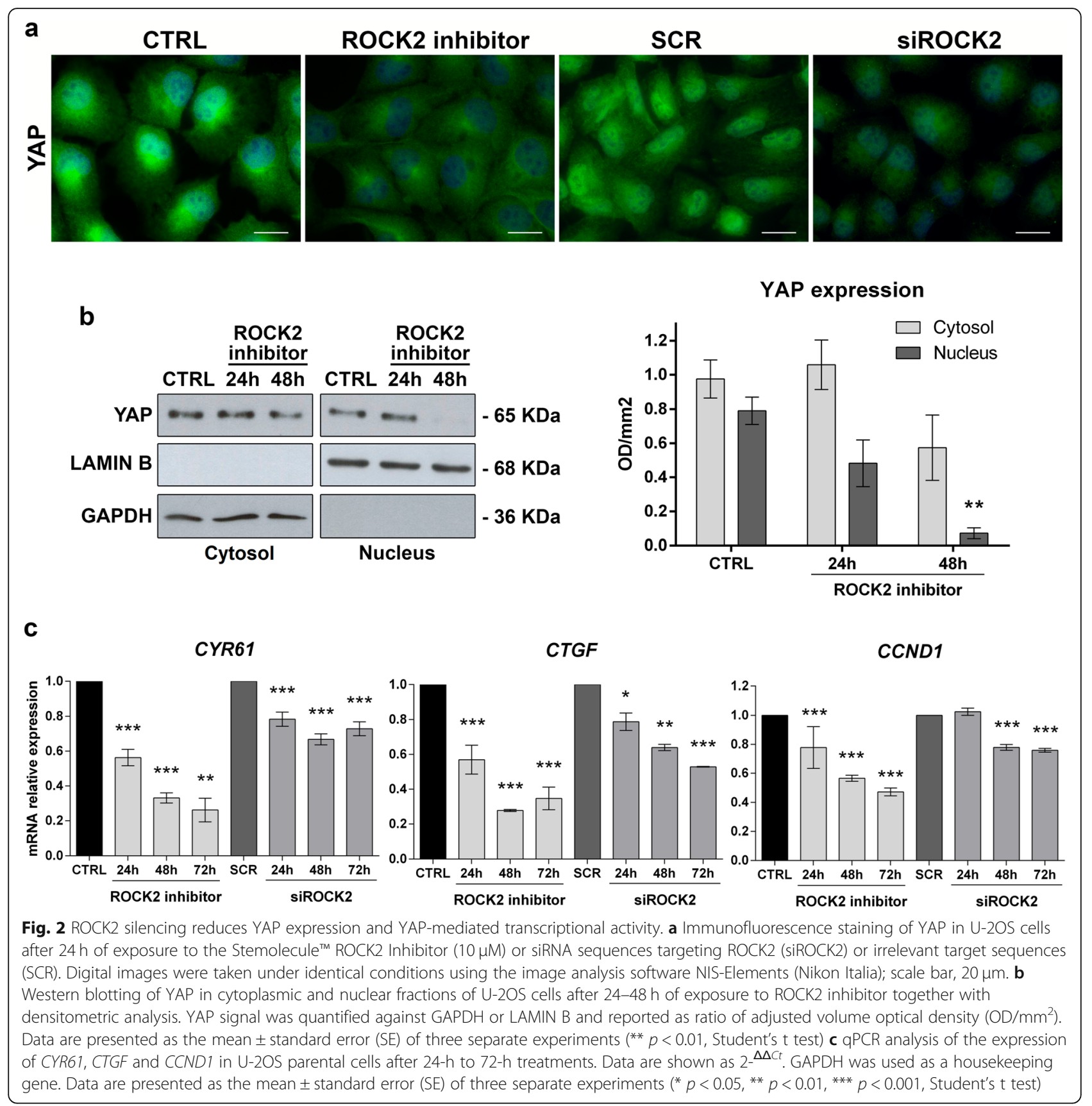

substantially improved the outcome of patients with localized disease, very few, if any, novel drugs are available for patients who fail to respond to first-line treatments or who have metastasis at diagnosis [32]. Our preclinical data indicate a potential therapeutic use for ROCK2 inhibitors. However, despite the interest from pharmaceutical companies in the ROCK pathway, only a few ROCK inhibitors have reached either clinical trials or the market [33]. In fact, only fasudil and ripasudil have been approved for clinical use to treat cerebral vasospasm and glaucoma [34, 35].
The potential safety concerns related to the use of ROCK inhibitors, together with the fact that the currently developed compounds have shown only moderate kinase selectivity (either against the two isoforms ROCK1 and ROCK2 or to a number of other kinases), have limited their use as systemic therapies in cancer clinical trials. Studying the downstream effectors of ROCK2 in the appropriate cellular context may thus allow the direct inhibition of this kinase to be bypassed, leading to the identification of alternative therapeutic approaches. In recent years, the connection between ROCK signaling and 
Table 3 HR of relapse for variables associated with RFS by univariate analysis in 175 patients (estimated by Cox proportional hazards regression multivariate analysis)

\begin{tabular}{llll}
\hline Variables associated with worse RFS & HR & $95 \% \mathrm{Cl}$ & $P$ value \\
\hline Response to chemotherapy: poor & 1.222 & $0.987-1.513$ & 0.066 \\
YAP localization: nuclear & 1.620 & $1.056-2.483$ & 0.027 \\
\hline
\end{tabular}

YAP activity in the context of cellular mechanoresponses has emerged. In particular, ROCK was found to be involved in the maintenance of the nuclear localization of YAP, thereby enhancing the activity of YAP $[11,14]$. In accordance with these results, we demonstrated that ROCK2 also promotes YAP activity in OS. In fact, in the tumors that developed in mice, the deprivation of ROCK2 occurred in parallel with the reduction in YAP expression and its transcriptional activity. In vitro, the inhibition of ROCK2 activity, either by pharmacological inhibition or silencing, induced a dose- and time-dependent reduction in the expression of YAP and its downstream target genes CTGF, CYR61 and CCND1, confirming the functional connection between these two intracellular mediators. YAP overexpression has been observed in several tumors, and high YAP expression levels have been correlated with poor patient prognosis in ovarian, non-small cell lung cancer and esophageal squamous cell carcinoma [36-38]. In OS, YAP is expressed in a vast majority of tumor samples [39]. However, only the presence of YAP in the nucleus, which is related to its transcriptional activity, but not the expression of ROCK2 or the general expression of YAP, was found to be associated with a higher probability of patient relapse. Accordingly, the incidence of metastasis was higher in patients that expressed YAP in the nuclei of tumor cells, and worse patient prognosis was associated with the level of YAP activity. In fact, the patients with the highest expression of YAP in the nucleus had a worse prognosis, either in terms of RFS or OVS, and died with a higher frequency than other patients. Therefore, these clinical data support the therapeutic potential of targeting YAP. Liu-Chittenden et al. [16] found that three compounds, which were related to porphyrin, out of $>3300$ drugs inhibited the transcriptional activity of YAP. One of

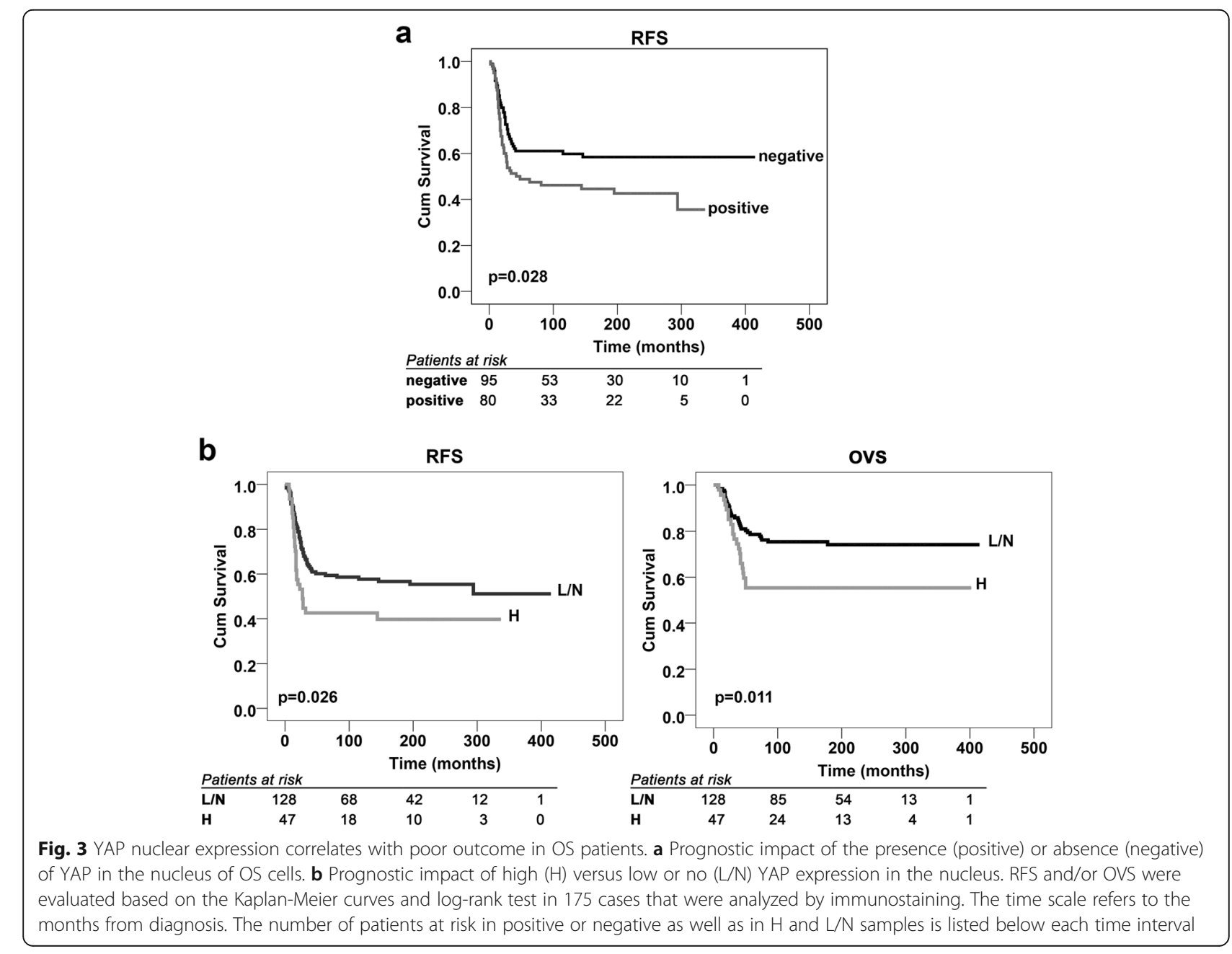




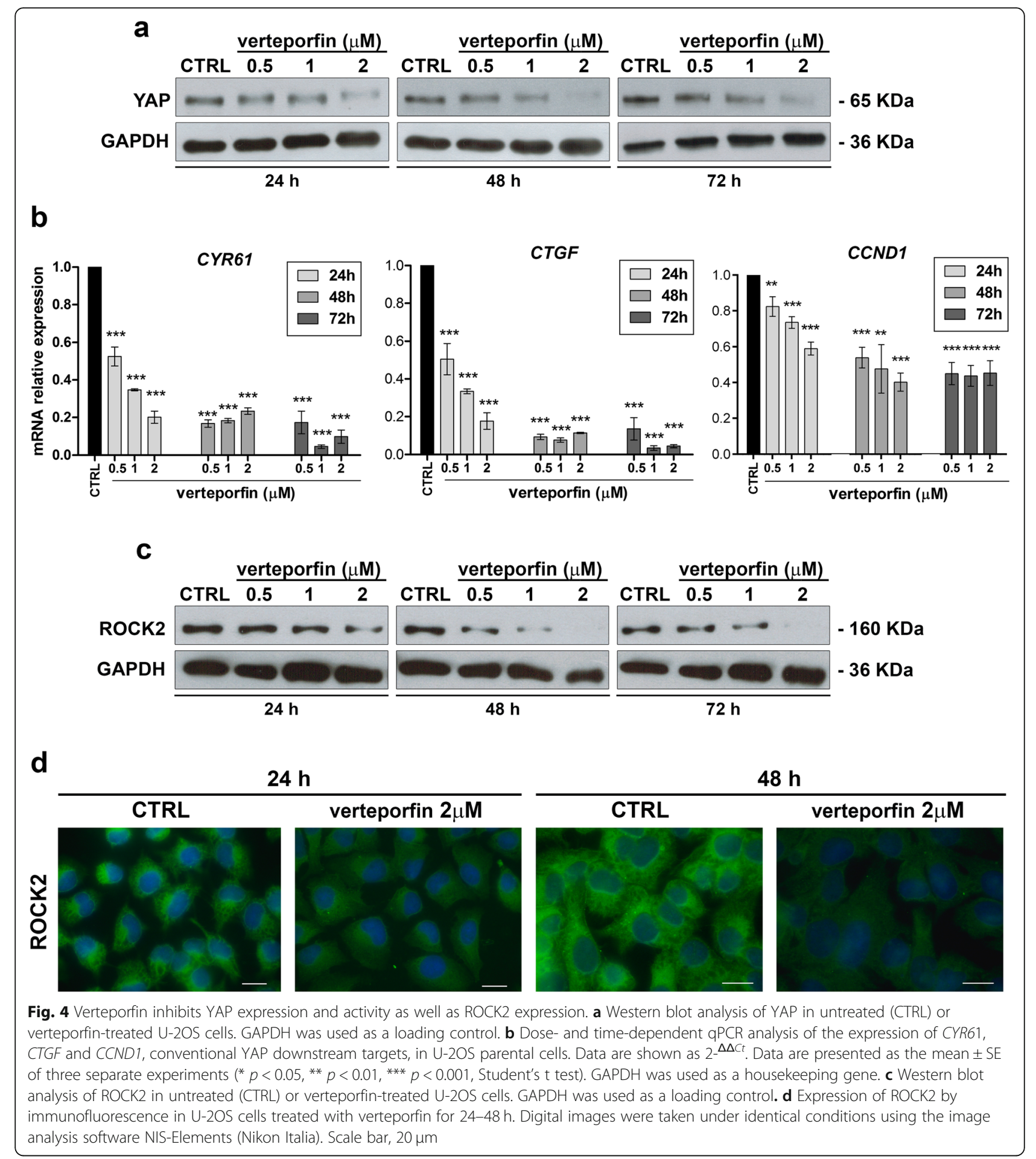

these compounds, verteporfin, is clinically used as a photosensitizer in photocoagulation therapy for macular degeneration [40]. More recently, verteporfin was shown to be effective at blocking the assembly of the functional YAP-TEAD transcription factor [16, 41, 42], suggesting the application of this compound as an anticancer agent. In OS, we showed that verteporfin, in addition to downregulating the expression and activity of YAP, significantly impaired tumor cell growth, either in standard and anchorage-independent conditions, and completely disrupted cell migration. YAP likely exerts its control on migration, at least in part, through the transcriptional regulation of the CTGF and CYR61 promoters. These genes, which belong to the CCN (Cyr61, CTGF and 


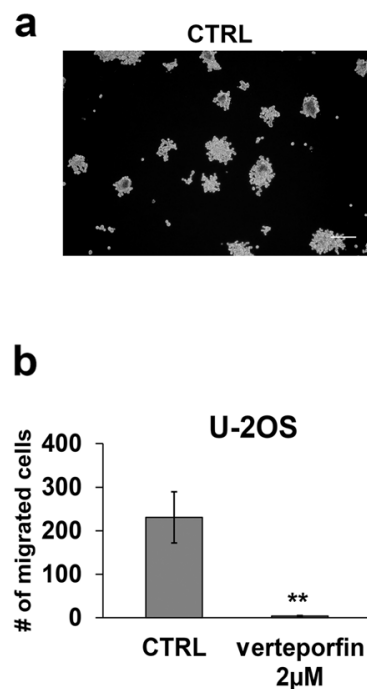

d
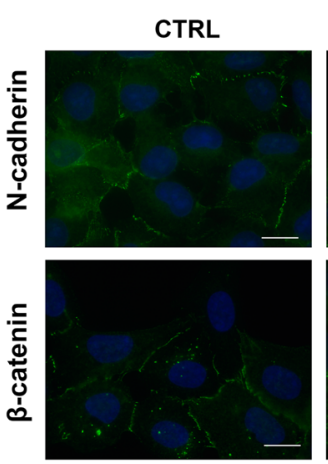

verteporfin $2 \mu \mathrm{M}$

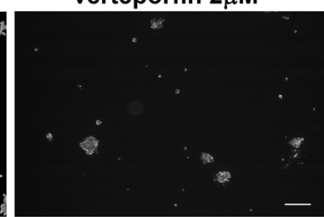

C
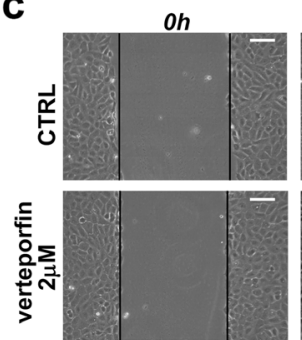

e
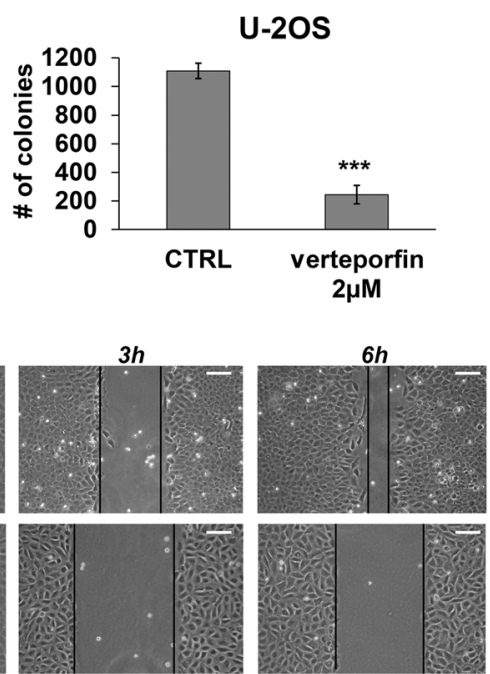

PDX-OS\#16-C2
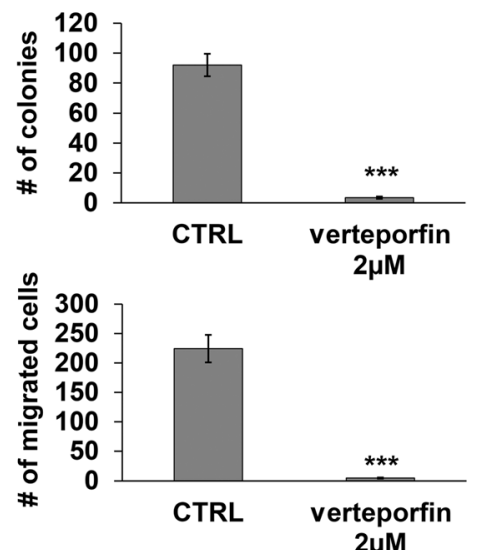

Fig. 5 Verteporfin reduces the aggressiveness of OS cells. a Effects of verteporfin on the growth of U-2OS cells in anchorage-independent conditions. Each column (right) represents the mean \pm SE of three separate experiments. Colonies were counted after 10 days. ${ }^{* *} P<0.0001$, paired Student's t test. Representative images (left) of spheroid colonies are shown. Scale bar, $200 \mu \mathrm{m} \mathbf{b}$ Effects of verteporfin on the migration of U-2OS cells in Transwell chambers. Each column represents the mean \pm SE of three separate experiments. ${ }^{* *} P<0.0001$, paired Student's $t$ test. c Effects of verteporfin after wound-healing assays scale bar, $100 \mu \mathrm{m} \mathbf{d}$ Immunofluorescence staining of $\mathrm{N}$-cadherin and $\beta$-catenin in U-2OS cells after $24 \mathrm{~h}$ of treatment with verteporfin. Digital images were taken in identical conditions using the image analysis software NIS-Elements; scale bar, $20 \mu \mathrm{m}$. e Effects of verteporfin on the growth of PDX-OS\#16-C2 in anchorage-independent conditions (upper) and on migration of these cells (lower). Each column represents the mean + SE of three separate experiments. ${ }^{* * *} P<0.0001$, paired Student's $t$ test

Nephroblastoma overexpressed gene) family [43], promote the epithelial-mesenchymal transition (EMT) process, allowing cancer cells to migrate and to disseminate to distant organs [44-46]. The overexpression of Cyr61 (CCN1) in the low-metastatic variant of the human SaOS-2 OS cell line increased cell proliferation and promoted lung metastasis [47], and both Cyr61 and CTGF (CCN2) have been implicated in the progression of bone metastases in other cancers [48]. Moreover, both Cyr61 and CTGF were shown to play a pivotal role in osteogenesis, and their expression decreased during the differentiation of OS cells to osteoblasts [49]. Therefore, the modulation of these genes by YAP may have a large impact on the progression of tumors that grow in the bone microenvironment, such as primary bone tumors and bone metastases. In addition to reducing the expression of CTGF and CYR61, our findings indicate that verteporfin also affects the ROCK2 protein, increases the expression and recruitment of $\mathrm{N}$ cadherin and $\beta$-catenin to the cell membrane. A positivefeedback mechanism between YAP and ROCK2 has been recently demonstrated by Sugimoto et al. [50], who showed that in response to extracellular matrix rigidity, ROCK2 enhances the activation of YAP, and YAP, in turn, induces ROCK2 expression by directly activating the ROCK2 promoter. Our results are in line with these findings and suggest that targeting YAP could be a rational 
strategy to inhibit multiple effects of the ROCK2/YAP axis that affect the invasive phenotype of tumor cells. Interestingly, YAP also plays important roles in immune cells and is involved in drug resistance [51-53], further supporting the systemic use of YAP inhibitors, such as verteporfin, as adjuvant agents to potentiate chemotherapy. Although YAP-independent effects have also been described for verteporfin, supporting the view that this compound is a multitarget drug that interacts with several proteins involved in major cellular processes, this apparent lack of specificity does not preclude its possible clinical use. This drug still has the advantage of being an FDA-approved photodynamic therapy, and for rare tumors, such as OS, this approval could make a difference.

Some efficacy of agents like pazopanib, which were reported to inhibit multiple targets including YAP [54], have been reported on case reports [55, 56], further supporting the investment in this area of research.

\section{Conclusion}

Very few, if any, effective treatment options exist for OS patients with metastatic disease. Thus, we desperately need to identify the pathways that promote metastasis and to determine how these pathways act in this specific cellular context. This paper suggests that ROCK2 is an important driver of OS migration and metastasis and provides evidence that the dysregulation of ROCK2 sustains YAP activity. Patients with the nuclear expression of YAP have a worse prognosis due to a higher incidence of metastasis and may benefit from drugs, such as verteporfin, that inhibit YAP activity. We showed that this agent inhibits YAP transcriptional activity and decreases ROCK2 expression, thus activating a positive-feedback loop that remarkably impacts OS growth and dissemination.

\section{Supplementary information}

Supplementary information accompanies this paper at https://doi.org/1 0.1186/s13046-019-1506-3.

Additional file 1: Figure S1. (a) Evaluation of expression and intracellular localization of ROCK2, N-cadherin and $\beta$-catenin in ROCK2 depleted U-2OS cell variants by immunoflourescence. Digital images were taken in identical conditions using the Image Analysis Software Nis Elements. Magnification $\times 600$, scale bar $20 \mu \mathrm{m}$ (b) Western blotting of ROCK2 in the same cellular variants to confirm ROCK2 depletion. GAPDH was used as a loading control. (c) Anchorage-independent growth of controls and ROCK2 depleted cells. Each column represents mean \pm SE of at least two separate experiments. ${ }^{* * *} p<0.0001$, paired Student's t-test; (d) Migration ability of controls and ROCK2 depleted cells. Each column represents mean \pm SE of three separate experiments. * $p<0.05$; ${ }^{* *} p<$ 0.01, paired Student's t-test.

Additional file 2: Figure S2. ROCK2 and YAP expression evaluated by the immunostaining of paraffin-embedded tissue sample. Representative images from another tumor developed after injection of control (U-2/ $\mathrm{SCR}$ ) or silenced cells (U-2/shROCK2\#78). Scale bar $50 \mu \mathrm{m} ; 200 \mathrm{x}$ of magnification with zoomed insert to show details.

Additional file 3: Figure S3. Dose- and time-dependent $\mathrm{QPCR}$ analysis of the expression of ROCK2 in U-2OS parental cells. Data indicate the percentage of ROCK2 mRNA inhibition with respect to control. Data are shown as mean $+/$ - SE of three separate experiments ${ }^{*} p<0.05$, ${ }^{* *} p<$ $0.01,{ }^{* * *} p<0.001$, Student's t test). GAPDH was used as a housekeeping gene.

Additional file 4: Figure S4. Western blotting of ROCK2 and YAP in PDX derived cell lines. Equal loading was monitored by anti-GAPDH blotting.

\section{Abbreviations}

CCND1: Cyclin D1; CTGF: Connective Tissue Growth Factor; CYR61: Cysteine Rich Angiogenic Inducer 61; DMSO: Dimetilsulfoxide; FBS: Fetal bovine serum; GAPDH: Glyceraldehyde-3-phosphate dehydrogenase; IHC: Immunohistochemistry; IMDM: Iscove's modified Dulbecco's medium; NA: Not available; NED: No evidence of disease; NSG: NOD Scid gamma; OS: Osteosarcoma; OVS: Overall survival; PDX: Patient-derived xenograft; qPCR: Quantitative real time polymerase chain reaction; REL: Relapsed; RFS: Relapse-free survival; ROCK1: Rho associated coiled-coil containing protein kinases 1; ROCK2: Rho associated coiled-coil containing protein kinases 2; YAP: Yes associated protein 1

\section{Acknowledgements}

We strongly acknowledge Cristina Ghinelli for her excellent technical assistance with the editing of the manuscript. We also would like to thank Valentina Chiadini and Paola De Sanctis for her technical help in the achievement of some experimental data.

\section{Authors' contributions}

MCM, CZ and KS were responsible for study design and critical revision of the manuscript. CZ and KS wrote the manuscript. MCM, CC, MC, SG, RSP were responsible for most of the experiments, analyzed the data, and prepared all the figures. MG was responsible for diagnosing osteosarcoma samples; MG and DMD were responsible for collecting osteosarcoma tissues samples. CF and MP were responsible for updating patient clinical information and follow-up as well as for analysis of clinical data. LL and PLL were responsible for the experiments in vivo. All authors read and approved the final manuscript.

\section{Funding}

This work is supported by grants received from: AIRC (IG 2013-14049 to KS); Alleanza Contro il Cancro (ACC-Genomics WG Sarcoma to KS); The European Union (ERANET TRANSCAN-2_TORPEDO ER-2015-2360405, to KS). MC received a fellowship from Horizon2020-IMI2-ITCC-P4 grant agreement $n^{\circ}$ 116064 to KS; SG received a fellowship from (ERANET TRANSCAN-2_TORPEDO ER-2015-2360405 to KS); RSP received a fellowship from the Associazione Onlus 'il Pensatore: Matteo Amitrano' and 'Liberi di Vivere Luca Righi'. The materials presented and views expressed here are the responsibility of the authors only. The sponsor takes no responsibility for any use made of the information set out.

\section{Availability of data and materials}

Further information and requests for resources and reagents should be directed to and will be fulfilled by the Lead Contact, Katia Scotlandi (katia. scotlandi@ior.it)

\section{Ethics approval and consent to participate}

The collection of human tumor tissues was approved by the ethical committee of the IRCCS Istituto Ortopedico Rizzoli (Prot. Gen 0021571 2013/ 06/28, Prot. Gen 0009323 2016/04/22, Prot. Gen 0009164 2017/09/22 and patient-informed consent forms were obtained for biobanking and/or for the establishment of PDX models; all methods were performed in accordance with institutional guidelines and Italian law.

All animal procedures were done in accordance with European directive 2010/63/UE and Italian Law (DL 26/2014); experimental protocols were reviewed and approved by the institutional animal care and use committee ("Comitato per il Benessere Animale") of the University of Bologna and by the Italian Ministry of Health with notice dated 1/26/2012 and authorizations 782/2015-PR, 208/2017-PR and 755/2018-PR. 


\section{Competing interests}

The authors declare that they have no competing interests.

\section{Author details}

'Department of Experimental, Diagnostic and Specialty Medicine, (DIMES), University of Bologna, Via Massarenti 9, 40126 Bologna, BO, Italy.

Experimental Oncology Laboratory, IRCCS Istituto Ortopedico Rizzoli, via di Barbiano 1/10, 40136 Bologna, Italy. ${ }^{3}$ Department of Pathology, IRCCS Istituto Ortopedico Rizzoli, Bologna, Italy. ${ }^{4}$ Clinica Ortopedica III, IRCCS Istituto Ortopedico Rizzoli, Bologna, Italy. ${ }^{5}$ Department of DIBINEM, University of Bologna, Bologna, Italy.

Received: 23 September 2019 Accepted: 12 December 2019 Published online: 26 December 2019

\section{References}

1. Harrison DJ, Schwartz CL. Osteogenic sarcoma: systemic chemotherapy options for localized disease. Curr Treat Options in Oncol. 2017;18:24.

2. Luetke A, Meyers PA, Lewis I, Juergens H. Osteosarcoma treatment - where do we stand? A state of the art review. Cancer Treat Rev. 2014:40:523-32.

3. Chou AJ, Geller DS, Gorlick R. Therapy for osteosarcoma: where do we go from here? Paediatr Drugs. 2008;10:315-27.

4. Duchman KR, Gao Y, Miller BJ. Prognostic factors for survival in patients with high-grade osteosarcoma using the surveillance, epidemiology, and end results (SEER) program database. Cancer Epidemiol. 2015;39:593-9 Elsevier Ltd.

5. Moon S, Yeon Park S, Woo PH. Regulation of the hippo pathway in cancer biology. Cell Mol Life Sci. 2018;75:2303-19.

6. Zanconato F, Cordenonsi M, Piccolo S. YAP/TAZ at the roots of Cancer. Cancer Cell. 2016;29:783-803.

7. Basu-Roy U, Bayin NS, Rattanakorn K, Han E, Placantonakis DG, Mansukhani A, et al. Sox2 antagonizes the hippo pathway to maintain stemness in cancer cells. Nat Commun. 2015;6:6411.

8. Chan LH, Wang W, Yeung W, Deng Y, Yuan P, Mak KK. Hedgehog signaling induces osteosarcoma development through Yap1 and H19 overexpression. Oncogene. 2014;33:4857-66.

9. Zhang $Y H$, Li B, Shen L, Shen Y, Chen XD. The role and clinical significance of YES-associated protein 1 in human osteosarcoma. Int J Immunopathol Pharmacol. 2013;26:157-67.

10. Low BC, Pan CQ, Shivashankar GV, Bershadsky A, Sudol M, Sheetz M. YAP/ TAZ as mechanosensors and mechanotransducers in regulating organ size and tumor growth. FEBS Lett. 2014;588:2663-70.

11. Dupont S, Morsut L, Aragona M, Enzo E, Giulitti S, Cordenonsi M, et al. Role of YAP/TAZ in mechanotransduction. Nature. 2011:474:179-83.

12. Kodaka M, Hata $Y$. The mammalian hippo pathway: regulation and function of YAP1 and TAZ. Cell Mol Life Sci. 2015;72:285-306.

13. Yu FX, Guan KL. The hippo pathway: regulators and regulations. Genes Dev. 2013;27:355-71.

14. Calvo F, Ege N, Grande-Garcia A, Hooper S, Jenkins RP, Chaudhry SI, et al. Mechanotransduction and YAP-dependent matrix remodelling is required for the generation and maintenance of cancer-associated fibroblasts. Nat Cell Biol. 2013;15:637-46.

15. Zucchini C, Manara MC, Pinca RS, De Sanctis P, Guerzoni C, Sciandra M, et al. CD99 suppresses osteosarcoma cell migration through inhibition of ROCK2 activity. Oncogene. 2014;33:1912-21.

16. Liu-Chittenden Y, Huang B, Shim JS, Chen Q, Lee SJ, Anders RA, et al. Genetic and pharmacological disruption of the TEAD-YAP complex suppresses the oncogenic activity of YAP. Genes Dev. 2012;26:1300-5.

17. Nanni P, Landuzzi L, Manara MC, Righi A, Nicoletti G, Cristalli C, et al. Bone sarcoma patient-derived xenografts are faithful and stable preclinical models for molecular and therapeutic investigations. Sci Rep. 2019. https:// doi.org/10.1038/s41598-019-48634-y.

18. Enneking WF, Spanier SS, Goodman MA. A system for the surgical staging of musculoskeletal sarcoma. Clin Orthop Relat Res. 1980;153:106-20.

19. Bacci G, Forni C, Longhi A, Ferrari S, Mercuri M, Bertoni F, et al. Local recurrence and local control of non-metastatic osteosarcoma of the extremities: a 27-year experience in a single institution. J Surg Oncol. 2007:96:118-23.

20. Ferrari S, Meazza C, Palmerini E, Tamburini A, Fagioli F, Cozza R, et al. Nonmetastatic osteosarcoma of the extremity. Neoadjuvant chemotherapy with methotrexate, cisplatin, doxorubicin and ifosfamide. An Italian Sarcoma Group study (ISG/OS-Oss). Tumori. II Pensiero Scientifico Editore s.r.l. 2014;100:612-9.
21. Ferrari S, Ruggieri P, Cefalo G, Tamburini A, Capanna R, Fagioli F, et al. Neoadjuvant chemotherapy with methotrexate, cisplatin, and doxorubicin with or without ifosfamide in nonmetastatic osteosarcoma of the extremity: an Italian sarcoma group trial ISG/OS-1. J Clin Oncol. 2012;30:2112-8.

22. Ferrari S, Smeland S, Mercuri M, Bertoni F, Longhi A, Ruggieri $P$, et al. Neoadjuvant chemotherapy with high-dose ifosfamide, high-dose methotrexate, cisplatin, and doxorubicin for patients with localized osteosarcoma of the extremity: a joint study by the italian and Scandinavian sarcoma groups. J Clin Oncol. 2005;23:8845-52.

23. Picci P, Bacci G, Campanacci M, Gasparini M, Pilotti S, Cerasoli S, et al. Histologic evaluation of necrosis in osteosarcoma induced by chemotherapy regional mapping of viable and nonviable tumor. Cancer. 1985;56:1515-21.

24. Bradburn MJ, Clark TG, Love SB, Altman DG. Survival analysis Part III: multivariate data analysis -- choosing a model and assessing its adequacy and fit. Br J Cancer. 2003:89:605-11.

25. Isfort I, Cyra M, Elges S, Kailayangiri S, Altvater B, Rossig C, et al. SS18-SSX-dependent YAP/TAZ signaling in synovial sarcoma. Clin Cancer Res. 2019:25:3718-31.

26. Hidalgo M, Budinska E, Amant F, Maelandsmo GM, Villanueva A, Jonkers J, et al. Patient-derived xenograft models: an emerging platform for translational cancer research. Cancer Discov. 2014;4:998-1013.

27. Lu W, Chao T, Ruiqi C, Juan S, Zhihong L. Patient-derived xenograft models in musculoskeletal malignancies. J Transl Med. 2018. https://doi.org/10.1186/ s12967-018-1487-6.

28. Stewart E, Federico SM, Chen X, Shelat AA, Bradley C, Gordon B, et al. Orthotopic patient-derived xenografts of paediatric solid tumours. Nature. 2017:549:96-100 Nature Publishing Group.

29. Rainusso N, Cleveland H, Hernandez JA, Quintanilla NM, Hicks J, Vasudevan $S$, et al. Generation of patient-derived tumor xenografts from percutaneous tumor biopsies in children with bone sarcomas. Pediatr Blood Cancer. 2019. https://doi.org/10.1002/pbc.27579.

30. Croft DR, Sahai E, Mavria G, Li S, Tsai J, Lee WM, et al. Conditional ROCK activation in vivo induces tumor cell dissemination and angiogenesis. Cancer Res. 2004;64:8994-9001

31. Lock FE, Ryan KR, Poulter NS, Parsons M, Hotchin NA. Differential regulation of adhesion complex turnover by ROCK1 and ROCK2. PLoS One. 2012;7:e31423.

32. Meazza C, Scanagatta P. Metastatic osteosarcoma: a challenging multidisciplinary treatment. Expert Rev Anticancer Ther. 2016;16:543-56.

33. Feng $Y$, LoGrasso PV, Defert $O$, Li R. Rho kinase (ROCK) inhibitors and their therapeutic potential. J Med Chem. 2016;59:2269-300.

34. Liu GJ, Wang ZJ, Wang YF, Xu LL, Wang XL, Liu Y, et al. Systematic assessment and meta-analysis of the efficacy and safety of fasudil in the treatment of cerebral vasospasm in patients with subarachnoid hemorrhage. Eur J Clin Pharmacol. 2012;68:131-9.

35. Yamamoto K, Maruyama K, Himori N, Omodaka K, Yokoyama Y, Shiga Y, et al. The novel rho kinase (ROCK) inhibitor K-115: a new candidate drug for neuroprotective treatment in glaucoma. Invest Ophthalmol Vis Sci. 2014;55:7126-36.

36. Xia Y, Chang $T$, Wang Y, Liu Y, Li W, Li M, et al. YAP promotes ovarian cancer cell tumorigenesis and is indicative of a poor prognosis for ovarian cancer patients. PLoS One. 2014:9:e91770 [cited 2019 Sep 5].

37. Cheng H, Zhang Z, Rodriguez-Barrueco RR, Borczuk A, Liu H, Yu J, et al. Functional genomics screen identifies YAP1 as a key determinant to enhance treatment sensitivity in lung cancer cells. Oncotarget. 2016;7: 28976-88 Impact Journals LLC.

38. Muramatsu T, Imoto I, Matsui T, Kozaki K-I, Haruki S, Sudol M, et al. YAP is a candidate oncogene for esophageal squamous cell carcinoma. Carcinogenesis. 2011;32:389-98.

39. Bouvier C, Macagno N, Nguyen Q, Loundou A, Jiquet-Jiglaire C, Gentet JC, et al. Prognostic value of the hippo pathway transcriptional coactivators YAP/TAZ and beta1-integrin in conventional osteosarcoma. Oncotarget. 2016;7:64702-10.

40. Michels S, Schmidt-Erfurth U. Photodynamic therapy with verteporfin: a new treatment in ophthalmology. Semin Ophthalmol. 2001;16:201-6.

41. Brodowska K, Al-Moujahed A, Marmalidou A, Meyer Zu Horste M, Cichy J, Miller JW, et al. The clinically used photosensitizer Verteporfin (VP) inhibits YAP-TEAD and human retinoblastoma cell growth in vitro without light activation. Exp Eye Res. 2014;124:67-73.

42. Wang C, Zhu X, Feng W, Yu Y, Jeong K, Guo W, et al. Verteporfin inhibits YAP function through up-regulating 14-3-3sigma sequestering YAP in the cytoplasm. Am J Cancer Res. 2016:6:27-37.

43. Li J, Ye L, Owen S, Weeks HP, Zhang Z, Jiang WG. Emerging role of CCN family proteins in tumorigenesis and cancer metastasis. Int J Mol Med. 2015; 36:1451-63. 
44. Hou CH, Lin FL, Hou SM, Liu JF. Cyr61 promotes epithelial-mesenchymal transition and tumor metastasis of osteosarcoma by Raf-1/MEK/ERK/Elk-1/ TWIST-1 signaling pathway. Mol Cancer. 2014. https://doi.org/10.1186/14 76-4598-13-236.

45. Hou CH, Yang RS, Tsao YT. Connective tissue growth factor stimulates osteosarcoma cell migration and induces osteosarcoma metastasis by upregulating VCAM-1 expression. Biochem Pharmacol. 2018;155:71-81.

46. Habel N, Stefanovska B, Carene D, Patino-Garcia A, Lecanda F, Fromigue O. CYR61 triggers osteosarcoma metastatic spreading via an IGF1Rbetadependent EMT-like process. BMC Cancer. 2019;19:62.

47. Sabile AA, Arlt MJE, Muff R, Bode B, Langsam B, Bertz J, et al. Cyr61 expression in osteosarcoma indicates poor prognosis and promotes intratibial growth and lung metastasis in mice. J Bone Miner Res. 2012;27:58-67.

48. Chen PC, Cheng HC, Yang SF, Lin CW, Tang CH. The CCN family proteins: modulators of bone development and novel targets in bone-associated tumors. Biomed Res Int. 2014. https://doi.org/10.1155/2014/437096.

49. Perbal B, Zuntini M, Zambelli D, Serra M, Sciandra M, Cantiani L, et al. Prognostic value of CCN3 in osteosarcoma. Clin Cancer Res. 2008;14:701-9.

50. Sugimoto W, Itoh K, Mitsui Y, Ebata T, Fujita H, Hirata H, et al. Substrate rigidity-dependent positive feedback regulation between YAP and ROCK2. Cell Adhes Migr. 2018;12:101-8.

51. Zhang $Y$, Zhang $H$, Zhao B. Hippo signaling in the immune system. Trends Biochem Sci. 2018:43:77-80.

52. Zhao $Y$, Yang $X$. The hippo pathway in chemotherapeutic drug resistance. Int J Cancer. 2015;137:2767-73.

53. Ferraiuolo M, Pulito C, Finch-Edmondson M, Korita E, Maidecchi A, Donzelli $S$, et al. Agave negatively regulates YAP and TAZ transcriptionally and posttranslationally in osteosarcoma cell lines. Cancer Lett. 2018;433:18-32.

54. Oku Y, Nishiya N, Shito T, Yamamoto R, Yamamoto Y, Oyama C, et al. Small molecules inhibiting the nuclear localization of YAP/TAZ for chemotherapeutics and chemosensitizers against breast cancers. FEBS Open Bio. 2015;5:542-9,

55. Umeda K, Kato I, Saida S, Okamoto T, Adachi S. Pazopanib for second recurrence of osteosarcoma in pediatric patients. Pediatr Int. 2017;59:937-8.

56. Longhi A, Paioli A, Palmerini E, Cesari M, Abate ME, Setola E, et al. Pazopanib in relapsed osteosarcoma patients: report on 15 cases. Acta Oncol. 2019;58:124-28.

\section{Publisher's Note}

Springer Nature remains neutral with regard to jurisdictional claims in published maps and institutional affiliations.

Ready to submit your research? Choose BMC and benefit from:

- fast, convenient online submission

- thorough peer review by experienced researchers in your field

- rapid publication on acceptance

- support for research data, including large and complex data types

- gold Open Access which fosters wider collaboration and increased citations

- maximum visibility for your research: over $100 \mathrm{M}$ website views per year

At $\mathrm{BMC}$, research is always in progress.

Learn more biomedcentral.com/submissions 